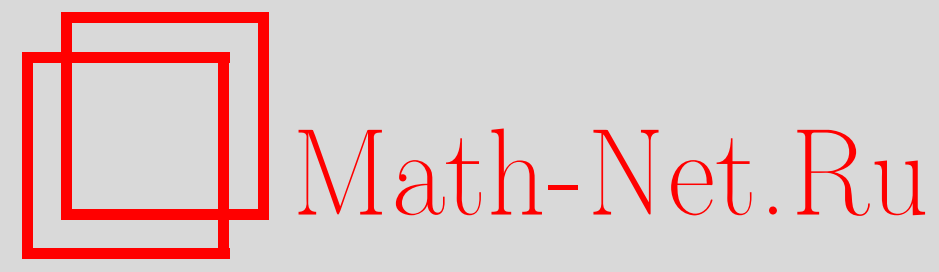

B. L. S. Prakasa Rao, On a characterization of stochastic processes by the absolute moments of stochastic integrals, Teoрия вероятн. и ее примен., 1998, том 43, выпуск 1, 189-191 DOI: https://doi.org/10.4213/tvp938

Использование Общероссийского математического портала Math-Net.Ru подразумевает, что вы прочитали и согласны с пользовательским соглашением http://www.mathnet.ru/rus/agreement

Параметры загрузки:

IP : 54.80 .73 .141

26 апреля 2023 г., 16:46:51

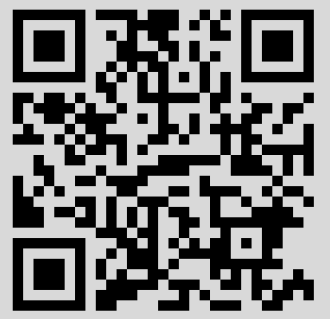


11. Szeidl L., Zolotarev V. M. Analytical representation of limit distributions for a class of random symmetric polynomials. - In: Probability Theory and Applications./Ed. by J. Galambos and I. Kátai. Dordrecht: Klüwer, 1992, p. 195-203.

12. Vladimirov V.S. Problems and Solutions in Mathematical Physics. Budapest: Müszaki Könyvkiadó, 1980 (in Hungarian).

13. Золотарев B. M. О представлении плотностей устойчивых законов специальными функциями. - Теория вероятн. и ее примен., 1994, т. 39, в. 2, с. 429-437.

Поступила в редакцию 10.VI.1997

(C) $1998 \mathrm{r}$.

RAO PRAKASA B. L. S.*

\title{
ON A CHARACTERIZATION OF STOCHASTIC PROCESSES BY THE ABSOLUTE MOMENTS OF STOCHASTIC INTEGRALS
}

\begin{abstract}
Условие идентичности двух непрерывных по вероятности стохастических процессов с независимыми стационарными симметричными приращениями дано в терминах абсолютных моментов стохастических интегралов.

Ключевые слова $и$ фразы: характеризация, стохастический интеграл, стохастический процесс, абсолютный момент.
\end{abstract}

1. Introduction. Braverman [1] gave a condition for the equality of the distributions of two independent symmetric random variables in terms of some absolute moments. Here we extend the result to characterize stochastic processes with independent stationary and symmetric increments. We first state a few definitions. Interalia, we extend the result of Braverman [1] to random vectors.

$\mathrm{D}$ e $\mathrm{f} \mathrm{i} \mathrm{i} \mathrm{t} \mathrm{i}$ o $\mathrm{n}$ 1. A random variable $X$ is said to be symmetric if $X$ and $-X$ are identically distributed.

$\mathrm{D}$ e f i $\mathrm{n}$ it i o $\mathrm{n}$ 2. A $k$-dimensional random vector $\mathrm{X}$ is said to be symmetric if $\lambda^{t} \mathbf{X}$ is symmetric for every $\lambda \in \mathbf{R}^{k}$.

Suppose $\mathbf{X} \equiv\{X(t), 0 \leqslant t \leqslant T\}$ is a stochastic process continuous in probability and with stationary independent symmetric increments. It can be checked that, for any continuous function $\gamma(t)$ defined on $[0, T]$, the stoch astic integral

$$
S_{\mathbf{X}} \equiv \int_{0}^{T} \gamma(t) d X(t)
$$

exists in probability and the characteristic function $\psi(\cdot)$ of $S_{\mathbf{X}}$ is given by the relation

$$
\log \psi(u)=\int_{0}^{T} \varphi(u \gamma(t)) d t
$$

where $\varphi(\cdot)$ is the $\log$ of the characteristic function of $X(t+1)-X(t)$. Note that the characteristic function of $X(t+1)-X(t)$ is a real-valued function by the symmetry of $X(t+1)-X(t)$, non-zero by the infinite divisibility of $X(t+1)-X(t)$ and does not depend on $t$ by the stationarity of the increments of the process X. In particular $\psi(\cdot)$ is

*Indian Statistical Institute, 7, S.J.S. Sansanwal Marg, New Delhi 110016, India. 
a real-valued function. In other words, $S_{\mathbf{X}}$ has a symmetric distribution. For details, see [2], [4] or [5].

2. Characterization. We now state the main result of this paper.

Theorem 1. Suppose $\mathrm{X} \equiv\{X(t), 0 \leqslant t \leqslant T\}$ and $\mathrm{Y} \equiv\{Y(t), 0 \leqslant t \leqslant T\}$ are two stochastic processes with stationary independent symmetric increments, continuous in probability and $X(0)=Y(0)=0$ a.s. Further suppose that there exists $p>0, p \neq 2 m$, $m=1,2, \ldots$, such that for some continuous function $\lambda(t)$ on $[0, T]$,

$$
\mathrm{E}\left|\int_{0}^{T} \lambda(t) d X(t)+\gamma U\right|^{p}=\mathbf{E}\left|\int_{0}^{T} \lambda(t) d Y(t)+\gamma V\right|^{p}
$$

for all $\gamma$ real, where $U$ and $V$ are non-zero symmetric and identically distributed random variables with absolute moments of order $p, U$ independent of $\mathbf{X}$ and $V$ independent of $\mathbf{Y}$ with $(\mathbf{X}, U)$ independent of $(\mathbf{Y}, V)$. Suppose that the characteristic functions of $X(t+$ 1) $-X(t)$ and $Y(t+1)-Y(t)$ have power series expansions. Then the processes $\mathrm{X}$ and $Y$ are identically distributed provided

$$
\int_{0}^{T}[\lambda(t)]^{k} d t \neq 0, \quad k \geqslant 2
$$

Before we give a proof of this theorem, we now state a result due to Braverman [1].

Theorem 2. Suppose that $p$ is a fixed positive number, $p \neq 2 m, m=1,2, \ldots$, the pairs $X, Z$ and $Y, U$ consist of independent symmetric random variables and $Z, U$ are identically distributed and non-zero. Further suppose that these random variables have finite absolute moments of order $p$ such that

$$
\mathbf{E}|X+t Z|^{p}=\mathbf{E}|Y+t U|^{p}
$$

for all $t$ real. Then $X$ and $Y$ are identically distributed random variables.

$\mathrm{R} \mathrm{e} \mathrm{m}$ a $\mathrm{r}$ k 1 . Braverman [1] pointed out that the result is not true for $p=2 m$. It is easy to extend Theorem 2 to random vectors.

Theorem 3. Suppose that $p$ is a fixed positive number, $p \neq 2 m, m=1,2, \ldots$, the pairs $(\mathbf{X}, U)$ and $(\mathbf{Y}, V)$ consist of symmetric $k$-dimensional random vectors $\mathbf{X}$ and $\mathbf{Y}, U, V$ non-zero identically distributed random variables and $\mathbf{X}$ independent of $U, \mathbf{Y}$ independent of $V$ with $(\mathbf{X}, U)$ independent of $(\mathbf{Y}, V)$. Further suppose that $(\mathbf{X}, U)$ and $(\mathbf{Y}, V)$ satisfy the condition

$$
\mathbf{E}\left|\boldsymbol{\lambda}^{t} \mathbf{X}+\beta U\right|^{p}=\mathbf{E}\left|\lambda^{t} \mathbf{Y}+\beta V\right|^{p}
$$

for all $\lambda \in \mathbf{R}^{k}$ and $\beta \in \mathbf{R}$. Then $\mathbf{X}$ and $\mathbf{Y}$ are identically distributed.

$\mathrm{P}$ r o o f. Note that $\lambda^{t} \mathbf{X}$ and $\lambda^{t} \mathbf{Y}$ are symmetrically distributed by Definition 2. An application of Theorem 2 implies that $\lambda^{t} X$ and $\lambda^{t} Y$ are identically distributed for all $\lambda \in \mathbf{R}^{k}$. Since this holds for all $\lambda \in \mathbf{R}^{k}$, an application of the Cramer-Wold technique proves that $\mathbf{X}$ and $\mathbf{Y}$ are identically distributed.

Let us now give the proof of Theorem 1.

$\mathrm{P}$ r $\circ$ o f. Let $g(\cdot)$ and $h(\cdot)$ be the $\log$ of the characteristic functions of $X(t+1)-X(t)$ and $Y(t+1)-Y(t)$ respectively. Note that $g(\cdot)$ and $h(\cdot)$ here are real-valued functions and do not depend on $t$. Let

$$
S_{\mathbf{X}}=\int_{0}^{T} \lambda(t) d X(t) \quad \text { and } \quad S_{\mathbf{Y}}=\int_{0}^{T} \lambda(t) d Y(t)
$$

It has already been pointed out that $S_{\mathbf{X}}$ and $S_{\mathbf{Y}}$ have symmetric distributions and the pairs $\left(S_{\mathbf{X}}, U\right)$ are independent and independent of $\left(S_{\mathbf{Y}}, V\right)$ which are independent. Ap- 
plying Theorem 2, it follows that $S_{\mathbf{X}}$ and $S_{\mathbf{Y}}$ are identically distributed. Hence

$$
\int_{0}^{T} g(u \lambda(t)) d t=\int_{0}^{T} h(u \lambda(t)) d t, \quad-\infty<u<\infty
$$

since the left side is the logarithm of the characteristic function of $S_{\mathbf{X}}$ and the right side is the logarithm of the characteristic function of $S_{\mathbf{Y}}$ (cf. [4]). The processes $\mathbf{X}$ and $\mathbf{Y}$ have moments of all orders and the terms of both the sides of (4) can be differentiated under the integral sign any number of times since the characteristic functions of $X(t+1)-X(t)$ and $Y(t+1)-Y(t)$ have power series expansions. We obtain that

$$
\int_{0}^{T}(\lambda(t))^{k} g^{(k)}(u \lambda(t)) d t=\int_{0}^{T}(\lambda(t))^{k} h^{(k)}(u \lambda(t)) d t
$$

where $g^{(k)}(u)$ denotes the $k$ th derivative of $g(\cdot)$ at $u$. Choosing $u=0$, we have

$$
g^{(k)}(0) \int_{0}^{T}(\lambda(t))^{k} d t=h^{(k)}(0) \int_{0}^{T}(\lambda(t))^{k} d t
$$

It follows that $g^{(k)}(0)=h^{(k)}(0)$ for $k \geqslant 2$ from (5) in view of condition (3). Observe that $g(\cdot)$ and $h(\cdot)$ are real-valued functions with $g(0)=h(0)=0$ and $g(-u)=g(u)$. Expanding the functions $g$ and $h$ in Taylor series expansions in a neighbourhood of zero, we obtain that $g(u)=h(u)$ in a neighbourhood of zero. Since the characteristic functions $e^{g(u)}$ and $e^{e(u)}$ have power series expansions, it follows that

$$
e^{g(u)}=e^{h(u)}, \quad-\infty<u<\infty .
$$

Hence the distributions of $X(t+1)-X(t)$ and $Y(t+1)-Y(t)$ are the same. In other words, the processes $\mathbf{X}$ and $\mathbf{Y}$ are identically distributed since the processes $\mathbf{X}$ and $\mathbf{Y}$ are completely determined by the distributions of $X(t+1)-X(t)$ and $Y(t+1)-Y(t)$ respectively under the hypotheses $X(0)=Y(0)=0$ a.s. stated above.

$\mathrm{R}$ e $\mathrm{m}$ a $\mathrm{r} 2$. If $p=2 m$ for some integer $m \geqslant 1$ in Theorem 1 , it is easy to check that

$$
\mathbf{E}\left[S_{\mathbf{X}}\right]^{2 m}=\mathbf{E}\left[S_{\mathbf{Y}}\right]^{2 m}
$$

from (2) and $S_{\mathbf{X}}$ and $S_{\mathbf{Y}}$ are not necessarily identically distributed from Remark 1.

\section{REFERENCES}

1. Braverman M. Sh. On a property of absolute moments. - Theor. Probab. and Math. Statist., 1987, v. 34, p. 29-37.

2. Lukacs E., Laha R. G. Applications of Characteristic Functions. London: Griffin, 1964.

3. Rao Prakasa B. L. S. Characterization of stochastic processes determined up to shift. - Теория вероятн. и ее примен., 1975, т. XX, в. 3, с. 633-636.

4. Rao Prakasa B. L. S. Characterization of stochastic processes by stochastic integrals. - Adv. Appl. Probab., 1983, v. 15, № 1, p. 81-98.

5. Rao Prakasa B. L. S. Identifiability in Stochastic Models: Characterization of Probability Distributions. Boston: Academic Press, 1992. 